\title{
PREVALENCE AND FACTORS ASSOCIATED WITH SMOKELESS TOBACCO USE AMONG ADOLESCENTS LIVING IN TEA GARDENS OF DIBRUGARH DISTRICT, ASSAM- A CROSS-SECTIONAL STUDY
}

\author{
Gayotree Gogoi', Rashmi Ahmed², Rupali Baruah³, Manjit Boruah4
}

\begin{abstract}
${ }_{1}^{1}$ Postgraduate Trainee, Department of Community Medicine, Assam Medical College, Dibrugarh, Assam. ${ }^{2}$ Assistant Professor, Department of Community Medicine, Assam Medical College, Dibrugarh, Assam.

3 Professor and HOD, Department of Community Medicine, Assam Medical College, Dibrugarh, Assam.

${ }^{4}$ Assistant Professor, Department of Community Medicine, Assam Medical College, Dibrugarh, Assam.
\end{abstract}

ABSTRACT
BACKGROUND
Tobacco epidemic is a matter of concern across the globe. Use of smokeless tobacco products pose a major challenge, as they are
used in a variety of forms. Preventing smokeless tobacco use at adolescent age would provide an opportunity in prevention of non-
communicable diseases, particularly cancer.
The objective of this study is to assess the prevalence and factors associated with smokeless tobacco use among adolescents
living in tea gardens of Dibrugarh district, Assam.

\section{MATERIALS AND METHODS}

A community-based, cross-sectional study conducted from June 2016 to May 2017. Multistage sampling method was used to select 4 out of 144 tea gardens of Dibrugarh district of Assam. Data was collected by house-to-house survey using a pre-tested, predesigned proforma, interviewing 400 adolescents (both boys and girls). Bivariate and multivariate regression analysis of factors associated with smokeless tobacco use was done.

\section{RESULTS}

Gutka and khaini were the two smokeless tobacco forms used. Prevalence of current use of gutkha and khaini were $26.2 \%$ and $6.2 \%$ respectively. Male sex, late adolescent age, school dropouts, tobacco use by friends and ignorance about health hazards of tobacco were associated factors.

\section{CONCLUSION}

Smokeless tobacco use among adolescents of tea gardens of Assam is an area of concern and needs appropriate preventive measures to bring down the future morbidities and mortalities.

\section{KEYWORDS}

Smokeless Tobacco, Prevalence, Factors, Adolescents, Tea Garden.

HOW TO CITE THIS ARTICLE: Gogoi G, Ahmed R, Baruah R, et al. Prevalence and factors associated with smokeless tobacco use among adolescents living in tea gardens of Dibrugarh district, Assam- a cross-sectional study. J. Evolution Med. Dent. Sci. 2018;7(02):237-241, DOI: $10.14260 /$ jemds/2018/53

\section{BACKGROUND}

Tobacco use is the single greatest preventable cause of death in the world today, killing upto half of its users. Globally, more than 5 million deaths each year are attributed to tobacco use. If the current trend continues, tobacco will kill more than 8 million people per year by 2030. (1) Use of smokeless tobacco is an important area of public health concern, as it is used in a variety of forms in at least 70 countries and by more than 300 million people. Majority (89\%) of the smokeless tobacco users are from South-East Asia Region.(2) According to Global Youth Tobacco survey in India (2009), among school students aged 13 - 15 years the prevalence of smokeless tobacco use was found to be $9.0 \%$ (11.1\% among boys and 6.0\% among girls). (3)

'Financial or Other Competing Interest': The Study received financial assistance from Indian Council of Medical Research, New Delhi under MD/MS Thesis Support.

Submission 17-11-2017, Peer Review 23-12-2017,

Acceptance 29-12-2017, Published 08-01-2018.

Corresponding Author:

Dr. Gayotree Gogoi,

Postgraduate Trainee,

Department of Community Medicine,

Assam Medical College, Dibrugarh-786002, Assam.

E-mail: gayotreenrp7@gmail.com

DOI: $10.14260 /$ jemds $/ 2018 / 53$

\section{(c) (1) ()요}

Epidemiological studies suggested the carcinogenic nature of smokeless tobacco products. There are sufficient evidence to prove that smokeless tobacco causes precancerous oral lesions and cancers of the oral cavity, oesophagus and pancreas besides causing addiction. (4) Health risks increase with concurrent cigarette smoking.

Adolescence, being a vulnerable age group, the young growing minds fall easy prey to risky behaviours, tobacco use being one of them. The increased initiation of smokeless tobacco products at a young age may be caused by marketing strategies of the tobacco companies and introduction of new and attractive flavoured products. (2) Preventing smokeless tobacco use at adolescent age would provide an opportunity in prevention of non-communicable diseases, particularly cancer. Therefore, it is important to determine the burden of smokeless tobacco use in this age group as well as investigate its associated factors in order to take appropriate preventive measures against its consumption. (5)

The tea industry is a major industry of Assam, contributing immensely to the state's economy. The tea garden population constitutes approximately $1 / 5^{\text {th }}$ of the state's population. (6) Study conducted by Medhi GK et al (2006) among tea garden youths of Assam found high prevalence of alcohol and tobacco use among them with a prevalence of $38.1 \%$ tobacco use in the age group $15-19$ 
years. (7) Recent research works on smokeless tobacco use among adolescents of tea garden community are scarce. Thus, the present study is undertaken to assess the prevalence and factors associated with smokeless tobacco use among adolescents living in tea gardens of Dibrugarh district of Assam.

\section{MATERIALS AND METHODS Study Setting}

The study was conducted in Dibrugarh district of Assam, which is also known as the "Tea city of the North-East.' Dibrugarh district boasts of the highest amount of tea production in India with a total of 144 tea gardens, several of them dating back to the British era. The district has 7 development blocks. (8) It was a community-based crosssectional study conducted from June 2016 to May 2017 among the adolescent boys and girls residing in tea gardens of the district.

\section{Sample Size}

The sample size was calculated by using the formula $\mathrm{n}=\mathrm{z}^{2} \mathrm{pq} / \mathrm{d}^{2}$, where $\mathrm{z}=1.96, \mathrm{p}=$ anticipated prevalence, $\mathrm{q}=1-\mathrm{p}$, $\mathrm{d}=$ allowable error. Taking prevalence of smokeless tobacco use among tea garden youths (p) $52.5 \%$ (7) with $10 \%$ relative error (d) and 95\% confidence interval, the sample size was found to be 362 . Considering $10 \%$ non-response rate and rounding up the required sample size turned out to be 400 .

\section{Sampling Design}

Multistage sampling technique was used. Out of the 7 development blocks of the district, one block Lahoal was selected randomly which comprises of 18 tea gardens. Each tea garden of the block has an average adolescent population of 100 . Therefore, from the list of tea gardens of the selected block, 4 tea gardens were selected randomly to meet the sample size of 400. Then from each tea garden, 100 adolescents were selected by house-to-house visit.

\section{Ethical Issues}

Ethical clearance was obtained from the Institutional Ethics Committee (H) of Assam Medical College and Hospital, Dibrugarh. A written informed consent was obtained from adolescents aged 18 - 19 years and for 10 - 17 years adolescent boys and girls, assent was obtained from the study participants and a written informed consent from the guardians was obtained prior to the commencement of the study.

\section{Data Collection}

In each household, the presence of an adolescent boy or girl was ascertained and if present he or she was included in the study. Those adolescents not willing to give consent, severely ill, absent at the time of visit and pregnant adolescent girls were excluded from the study. The study participants were carefully briefed about the purpose of the study to ensure their full cooperation. Data was collected by interviewing the study participants using a pre-designed and pre-tested proforma. Questions on the use of common forms of smokeless tobacco namely gutka (mixture of areca nut, powdered tobacco, catechu and flavouring agents available in packets under different trade names), khaini (mixture of dried tobacco leaves and slaked lime) and pan with tobacco were included in the proforma.

\section{Statistics}

The study population was described by using rates, proportions, mean and standard deviation. Data was entered into SPSS, version 16.0 software. Analysis was done by using bivariate and multivariate logistic regression.

\section{Working Definitions \\ Ever User}

The study participant has used the smokeless tobacco form one or more times in his/ her life.

\section{Current User}

The study participant has used the smokeless tobacco form at least once during the past 30 days preceding the study.

\section{Never User}

The study participant has never used smokeless tobacco in his/ her life.

\section{RESULTS}

Out of the 400 study participants, 217 (54.2\%) were adolescent boys and 183 (45.8\%) were adolescent girls. The mean age group was $15.12 \pm 2.59$ years (range $10-19$ years). Only $1.7 \%$ of the participants were illiterate, while $23.7 \%$ were school dropouts. The socio-demographic characteristics of the participants are shown in Table 1.

Gutka and khaini were the two smokeless tobacco forms consumed by the study participants. The prevalence of ever use of gutka and khaini were $28.3 \%$ and $8.7 \%$ respectively and current use of gutka and khaini were $26.2 \%$ and $6.2 \%$ respectively (Table 2). Gutka was the predominant smokeless tobacco form used. High prevalence was seen among the adolescent boys $(46.1 \%$ were current gutka users) as compared to $2.7 \%$ adolescent girls currently using gutka. The participants preferred to use the cheaper smokeless tobacco products.

On bivariate analysis, it was revealed that late adolescent age group, male sex, school drop-outs, tobacco use by friends, lack of knowledge about health hazards of tobacco and not viewing any anti-tobacco messages on television were the factors found to be significantly associated with current gutka use (Table 3). After adjusting these variables to each other in the multivariate analysis, the most important factors associated with current gutka use were found to be male sex (AOR 37.58: 95\% CI 13.16 - 107.30), tobacco use by friends (AOR 33.80: 95\% CI 3.32 - 343.74) and late adolescent age group (AOR 8.22: 95\% CI 3.15 - 21.43). School drop-outs, not viewing any anti-tobacco messages on TV and lack of knowledge on health hazards of tobacco were other associated factors (Table 4). 


\begin{tabular}{|c|c|c|c|}
\hline \multicolumn{2}{|c|}{ Socio-Demographic Characteristics } & Number & \% \\
\hline \multirow{2}{*}{$\begin{array}{c}\text { Age Group } \\
\text { (in years) }\end{array}$} & $10-14$ & 142 & 35.5 \\
\cline { 2 - 4 } Sex & $15-19$ & 258 & 54.5 \\
\hline \multirow{2}{*}{ Religion } & Male & 217 & 45.8 \\
\cline { 2 - 4 } & Female & 183 & 93.3 \\
\hline \multirow{2}{*}{ Marital Status } & Hindu & 373 & 6.7 \\
\cline { 2 - 4 } & Christian & 27 & 1.7 \\
\cline { 2 - 4 } & Married & 7 & 98.3 \\
\hline \multirow{3}{*}{ Educational Status } & Unmarried & 793 & 1.7 \\
\cline { 2 - 4 } & Illiterate & 115 & 28.8 \\
\cline { 2 - 4 } & Primary School & 57 & 14.3 \\
\cline { 2 - 4 } & Middle School & 175 & 43.7 \\
\cline { 2 - 4 } & High School & 27 & 6.8 \\
\cline { 2 - 4 } & Higher Secondary & 19 & 4.7 \\
\hline \multirow{2}{*}{ Socio-Economic Class } & Class III & 15 & 3.8 \\
\cline { 2 - 4 } & Cass IV & 262 & 65.5 \\
\cline { 2 - 4 } & Class V & 123 & 30.7 \\
\hline \multirow{2}{*}{ Type of Family } & Nuclear & 262 & 65.5 \\
\cline { 2 - 4 } & Joint & 138 & 34.5 \\
\hline
\end{tabular}

\begin{tabular}{|c|c|c|c|c|}
\hline \multirow{2}{*}{ Type of Smokeless Tobacco } & \multicolumn{2}{|c|}{ Ever User } & \multicolumn{2}{c|}{ Current User } \\
\cline { 2 - 5 } & Number & \% & Number & 26.2 \\
\hline Gutka & 113 & 28.3 & 105 & 6.2 \\
\hline Khaini & 35 & 8.7 & 25 & \\
\hline
\end{tabular}

\begin{tabular}{|c|c|c|c|c|c|}
\hline \multirow{2}{*}{\multicolumn{2}{|c|}{ Variables }} & \multicolumn{2}{|c|}{ Current Use } & \multirow{3}{*}{$\begin{array}{c}\text { Odd's Ratio 95\% CI } \\
\text { Reference }\end{array}$} & \multirow{4}{*}{$\begin{array}{c}\text { P-value } \\
0.000\end{array}$} \\
\hline & & \multirow{3}{*}{$\begin{array}{c}\text { Yes (\%) } \\
13(9.2) \\
92(35.7)\end{array}$} & \multirow{2}{*}{$\begin{array}{c}\text { No (\%) } \\
129(90.8)\end{array}$} & & \\
\hline & $10-14$ & & & & \\
\hline Age Group (In years) & $15-19$ & & $166(64.3)$ & $5.50(2.94-10.27)$ & \\
\hline \multirow{2}{*}{ Sex } & Female & $5(2.7)$ & $178(97.3)$ & Reference & \multirow{2}{*}{0.000} \\
\hline & Male & $100(46.1)$ & $117(53.9)$ & $30.42(12.63-76.96)$ & \\
\hline \multirow{2}{*}{ Drop Out of School } & No & $58(19.0)$ & $247(81.0)$ & Reference & \multirow{2}{*}{0.000} \\
\hline & Yes & $47(49.5)$ & $48(50.5)$ & 4.17 (2.54-6.83) & \\
\hline \multirow{2}{*}{ Father's Education } & Illiterate & $23(21.1)$ & $86(78.9)$ & Reference & \multirow{2}{*}{0.153} \\
\hline & Literate & $82(28.2)$ & $209(71.8)$ & $1.46(0.86-2.48)$ & \\
\hline \multirow{2}{*}{ Mother's Education } & Illiterate & $68(26.0)$ & $194(74.0)$ & Reference & \multirow{2}{*}{0.853} \\
\hline & Literate & 37 (26.8) & $101(73.2)$ & $1.04(0.65-1.66)$ & \\
\hline \multirow{2}{*}{ Type of Family } & Nuclear & $75(28.8)$ & $187(71.4)$ & $0.69(0.42-1.12)$ & \multirow{2}{*}{0.138} \\
\hline & Joint & $30(21.7)$ & $108(78.3)$ & Reference & \\
\hline \multirow{3}{*}{ Socio-Economic Class } & Class III & $5(33.3)$ & $10(66.7)$ & $1.54(0.50-4.69)$ & 0.538 \\
\hline & Class IV & $64(24.4)$ & $198(75.6)$ & Reference & \\
\hline & Class V & $36(29.3)$ & $87(70.7)$ & $1.28(0.79-2.06)$ & 0.312 \\
\hline \multirow{2}{*}{ Tobacco Use by Friends } & No & $1(0.7 \%)$ & 135 (99.3) & Reference & \multirow{2}{*}{0.000} \\
\hline & Yes & $104(39.4)$ & $160(60.6)$ & $87.75(12.08-637.23)$ & \\
\hline \multirow{2}{*}{$\begin{array}{c}\text { Tobacco Use by Family } \\
\text { Members }\end{array}$} & No & $8(22.2)$ & $28(77.8)$ & Reference & \multirow[b]{2}{*}{0.566} \\
\hline & Yes & $97(26.6)$ & $267(73.4)$ & $1.27(0.56-2.88)$ & \\
\hline \multirow{2}{*}{$\begin{array}{c}\text { Knowledge about Hazards } \\
\text { of Tobacco }\end{array}$} & Yes & $55(21.1)$ & $206(78.9)$ & Reference & \multirow{2}{*}{0.001} \\
\hline & No & $50(36.0)$ & $89(64.0)$ & $2.10(91.33-3.32)$ & \\
\hline \multirow{2}{*}{$\begin{array}{c}\text { Seen Anti-Tobacco } \\
\text { Messages on TV }\end{array}$} & Yes & $73(23.5)$ & $238(76.5)$ & Reference & \multirow{2}{*}{0.019} \\
\hline & No & $32(36.0)$ & $57(64.0)$ & $1.83(1.10-3.03)$ & \\
\hline
\end{tabular}




\begin{tabular}{|c|c|c|c|}
\hline \multicolumn{2}{|c|}{ Variables } & \multirow[t]{2}{*}{$\begin{array}{c}\text { Adjusted Odd's Ratio } \\
(95 \% \mathrm{CI})\end{array}$} & \multirow{3}{*}{$\begin{array}{c}\text { P-value } \\
0.000\end{array}$} \\
\hline \multirow{2}{*}{$\begin{array}{l}\text { Age Group } \\
\text { (in years) }\end{array}$} & $10-14$ & & \\
\hline & $15-19$ & $8.22(3.15-21.43)$ & \\
\hline \multirow{2}{*}{ Sex } & Female & & \multirow{2}{*}{0.000} \\
\hline & Male & $37.58(13.16-107.30)$ & \\
\hline \multirow{2}{*}{ Drop Out of School } & No & & \multirow{2}{*}{0.002} \\
\hline & Yes & $3.21(1.54-6.68)$ & \\
\hline \multirow{2}{*}{ Tobacco Use by Friends } & No & & \multirow{2}{*}{0.003} \\
\hline & Yes & $33.80(3.32-343.74)$ & \\
\hline \multirow{2}{*}{$\begin{array}{l}\text { Knowledge about } \\
\text { Hazards of Tobacco }\end{array}$} & Yes & & \multirow{2}{*}{0.031} \\
\hline & No & $2.21(1.07-4.56)$ & \\
\hline \multirow{2}{*}{$\begin{array}{l}\text { Seen Anti-Tobacco } \\
\text { Messages on TV }\end{array}$} & Yes & & \multirow{2}{*}{0.001} \\
\hline & No & $4.97(1.99-12.29)$ & \\
\hline
\end{tabular}

\section{DISCUSSION}

In the present study, the prevalence of ever use and current use of gutka were $28.3 \%$ and $26.2 \%$, respectively. Prevalence of gutka use among the adolescent boys and girls were $46.1 \%$ and $2.7 \%$ respectively. Bhaskar RK et al (2016) in their study in Kalaiya, Nepal found $8.4 \%$ gutka use among the study participants, which is lower than the present study finding. (9) Bardhan $\mathrm{T}$ et al (2015) in their study in Guwahati, Assam found $83.4 \%$ prevalence of gutka use and Kamate RP et al (2017) in their study in Belagavi, Karnataka observed 78.87\% prevalence of smokeless tobacco which were higher than the present study finding.(10),(11)

Prevalence of ever users and current users of khaini in the present study were found to be $8.7 \%$ and $6.2 \%$ respectively. Studies done by Bhaskar RK et al and Bardhan T et al found the prevalence of khaini use among adolescents to be $9.2 \%$ and $9.7 \%$ respectively, which were consistent with the present study finding. (9), (10) Khaini use is an age-old practice among the tea garden population of Assam. The tea garden workers use it while they pluck tea leaves in the gardens. They believed that using khaini would help in easy healing of insect bite wounds, which they get during work. They also used khaini to feel fresh to start the day. The present study findings suggest that khaini use start right from the adolescent age in the tea garden population. Easy availability and accessibility of smokeless tobacco products also contribute to their use.

Multivariate analysis revealed that gutka use was found to be associated significantly with late adolescent age group, male sex, school drop-out, tobacco use by friends, lack of knowledge about hazards of tobacco use and not viewing any anti-tobacco messages on television. Almost similar findings were obtained by Bhaskar RK et al in their study which showed significant association of tobacco use with male sex, family members using tobacco and exposure to tobacco use at home on multivariate analysis. (9) Study by Kumar V et al (2014) in Delhi showed that on bivariate analysis male sex, socio-economic class and those getting higher pocket money were significantly associated with current tobacco use. (12)

\section{CONCLUSION}

The present study brings to light the prevalence and factors associated with smokeless tobacco use among adolescent boys and girls of the tea garden community. Prevalence was significantly high among the late adolescent age group, the adolescent boys and the school drop-outs. Tobacco use by peer groups and poor knowledge about adverse health effects of tobacco also influenced its use. Appropriate preventive measures is the need of the hour to address tobacco addiction among adolescents to prevent future morbidities and mortalities. The adolescents should be educated and counselled regarding the short-term and long-term harmful effects of tobacco use. Parents, teachers and media can play an important role in this regard. Adolescent clubs and nongovernment organisations can be utilised to reach the out of school adolescents. Strict implementation of tobacco control legislations can further help to curb down the use of tobacco products among adolescents.

\section{ACKNOWLEDGEMENT}

We would like to acknowledge Indian Council of Medical Research, New Delhi for their financial assistance and the study participants for their active participation in our study.

\section{REFERENCES}

[1] MPOWER. A policy package to reverse the tobacco epidemic. World Health Organization Geneva: 2008.

[2] Smokeless Tobacco and Public Health: a global perspective. U.S. Department of Health and Human Services, Centers for Disease Control and Prevention and National Institutes of Health, National Cancer Institute, 2014.

[3] Findings from the Global Youth Tobacco Survey (GYTS) and Global School Personnel Survey (GSPS). India: World Health Organization, Ministry of Health and Family Welfare, Government of India, 2003-2009.

[4] Personal habits and indoor combustions: a review of human carcinogens, IARC Monographs on the evaluation of carcinogenic risks to humans. Lyon, France: World Health Organization, International Agency for Research on Cancer 2012.

[5] Ngahane BHM, Ekobo HA, Kuaban C. Prevalence and determinants of cigarette smoking among college students: a cross-sectional study in Douala, Cameroon. Arch Public Health 2015;73:47.

[6] Medhi GK, Hazarika NC, Shah B, et al. Study of health problems and nutritional status of tea garden population of Assam. Indian J Med Sci 2006;60(12):496-505.

[7] Medhi GK, Hazarika NC, Mahanta J. Tobacco and alcohol use among the youth of the agricultural tea industry in Assam, India. Southeast Asian J Trop Med Public Health 2006;37(3):581-6. 
[8] Dibrugarh District, $\quad$ Assam. 2017. http://dibrugarh.nic.in/district.html.

[9] Bhaskar RK, Sah MN, Gaurav K, et al. Prevalence and correlates of tobacco use among adolescents in the schools of Kalaiya, Nepal: a cross-sectional questionnaire based study. Tobacco Induced Diseases 2016;14:11.

[10] Bardhan T, Saikia AM, Baruah R. Substance use among adolescents living in slums of Guwahati city, Assam: a growing public health concern. Int J Med \& Public Health 2015;5(4):279-82.
[11] Kamate RP, Ashtagi GS, Mallapur MD. Prevalence of substance use among adolescents in urban slums of Belagavi. Indian J Health Sci Biomed Res KLEU 2017;10(1):25-8.

[12] Kumar V, Talwar R, Roy N, et al. Psychosocial Determinants of Tobacco Use among School Going Adolescents in Delhi, India. Article ID 170941, Journal of Addiction 2014;1-6. 